\title{
Reduced erythrocyte carbonic anhydrase activity by Swietenia macrophylla seeds in diabetic rats
}

\author{
Abstract \\ Background: We have previously reported that the CA activity is associated with advance \\ glycation end product in insulin resistance condition. Our earlier report also revealed \\ that Swietenia macrophylla effectively reduces the blood glucose levels in streptozotocin \\ induced diabetic rats.
}

Aim: The present study aims to find out if there is any effect of these plant extract on CA activity in Diabetic rat model.

Materials and methods: Streptozotocin was used to induce diabetes except in the control group. The activities of the Carbonic anhydrase in plasma and other biochemical parameters were estimated using standardized methods.

Results: Our Results demonstrate the erythrocyte CA activity is positively correlated with the blood glucose as well as total cholesterol, triglyceride, LDL cholesterol levels. There is reduction of CA activity under the effect of these extract along with effective lowering of blood glucose and the above lipid parameters.

Conclusions: The extract of Swietenia macrophylla seeds effectively inhibits erythrocyte CA activity and has potential for use to control Diabetes Mellitus and prevent complications.

Keywords: diabetes mellitus, swietenia macrophylla seeds, carbonic anhydrase

\author{
Volume 2 Issue 2 - 2015
}

\author{
Moumita Dutta,' Utpal Kumar Biswas, ${ }^{2}$ \\ Runu Chakraborty,' Piyasa Banerjee, ' Arun \\ Kumar, ${ }^{3}$ Utpal Raychaudhuri' \\ 'Department of Food Technology and Biochemical Engineering, \\ Jadavpur University, India \\ ${ }^{2}$ Department of Biochemistry, Nil Ratan Sircar Medical College, \\ India \\ ${ }^{3}$ Department of Biochemistry, Manipal College of Medical
} Science, India

\section{Correspondence: Utpal Raychaudhuri, Head of the Department of Food Technology and Biochemical Engineering, Jadavpur University, India, Tel +91 9830329408} Email utpal3I@hotmail.com

Received: February 03, 2015 | Published: April I3, 2015
Abbreviations: CAs, carbonic anhydrases; NO, nitric oxide; FBG, fasting blood glucose; TG, triglyceride

\section{Introduction}

Carbonic anhydrases (CAs, EC 4) are zinc containing metalloenzymes. The active site of these enzymes contains a $\mathrm{Zn}$ (II) ion Co-ordinated by three histidine residues and a water molecule/ hydroxide ion. Four distinct gene families encode them and distributed throughout the phylogenetic tree. Presently 16 different CA isoforms of alpha family have been isolated and characterized in mammals. They catalyze the rapid inter conversion of carbon dioxide and water to bicarbonate and protons, a reversible reaction that occurs relatively slowly in the absence of a catalyst. ${ }^{1,2}$

Several important physiological and pathological functions are played by the CA isozymes present in organisms, related to respiration and transport of $\mathrm{CO}_{2}$ and bicarbonate between metabolizing tissues and the lungs, $\mathrm{pH}$ and $\mathrm{CO}_{2}$ homeostasis, electrolyte secretion in a variety of tissues or organs. These enzymes play very important role in providing biocarbonate as substrate for carboxylation in different essential metabolic pathways which include gluconeogenesis and synthesis of some amino acids (pyruvate carboxylase) lipogenesis (pyruvate carboxylase and acetyl coA carboxylase), ureagenesis (carbamoyl synthase I) and pyrimidine synthesis ( Carbamoyl phosphate synthase II). ${ }^{3}$

The erythrocyte contains CA I and CA II isoenzymes. Though CA II normally accounts for only $14-17 \%$ of the CA in RBC and CA I accounts for the rest, it has been estimated that CA II contributes about $90 \%$ of the CA activity of erythrocytes in vivo. The function of carbonic anhydrase in the blood is primarily as an accelerator of the elimination of $\mathrm{CO}_{2}$ in the lungs. Metabolic $\mathrm{CO}_{2}$ produced in the tissues, must be delivered to the circulating erythrocytes to be rapidly converted to $\mathrm{HCO} 3$ by these enzymes which also catalyze the reverse reaction in the lung capillaries to excrete that $\mathrm{CO}_{2}$ from the lungs. ${ }^{4}$

Mammalian carbonic anhydrases also catalyze the hydrolysis of some esters and the hydration of aldehydes. Their activities with these other substrates may be substantially different from their activities with carbon dioxide as substrate. ${ }^{1,5-8} \mathrm{~A}$ study has reported the generation of nitric oxide (NO) from nitrite by the action of this enzyme. Changes in catalytic activities of carbonic anhydrase had been observed in various diseases. We have previously reported the changes of CA activity with thyroid disorders, ${ }^{9}$ psoriasis ${ }^{6}$ and hypertension. ${ }^{5}$ We have also demonstrated the increase of CA activity in patients with insulin resistance and this activity was associated with Methylglyoxal in the serum as well as in RB.C model. ${ }^{10}$

The catalytic and inhibitory mechanisms of these enzymes have been studied extensively. This has helped to design some potent inhibitors of clinical interest. ${ }^{11}$ The modulations of carbonic anhydrase activity of have been proposed for treatment and prophylaxis of obesity. ${ }^{12,13}$ Presently various types of phytoconstituents isolated from medicinal plants. Swietenia macrophylla is one of such plants. We have studied that the extract of Swietenia macrophylla seeds which is a not only a nontoxic one ${ }^{14}$ but also have a significant hypoglycemic effect and exhibited antioxidant property. ${ }^{14,15}$ Our earlier observation also revealed that aqueous extract of this plant's seeds help to regenerate the pancreatic $\beta$ - cells in the diabetic rats. ${ }^{16}$

Current study aims to observe whether the extract of this plant has any effect on the Erythrocyte CA activity in the streptozotocin induced diabetic rats and in the $R$ B.C models in vitro. 


\section{Material and methods}

\section{Preparation of extract of Swietenia macrophylla seeds}

Swietenia macrophylla seeds of were collected and authenticated (the voucher specimen Ref. no. CNH/I-I/54/2009/Tech. II/154). The seeds were, washed, shed-dried at room temperature, grinned to powder and sieved through 40 meshes. The extract was prepared by dissolving $200 \mathrm{mg}$ powder in one $\mathrm{ml}$ of distilled water and thereafter centrifuged at 3,000r.p.m for 15 minutes. The supernatant was collected by milipore filtration. The pure extract of Swietenia macrophylla thus obtained was stored in air tight glass vials. ${ }^{13,14}$

\section{Study animals}

6-8weeks aged healthy adult Wister albino rats of 98-110grams weight and both sexes were used for this study. Females were nulliparous and not pregnant. Before initiation, the rats were allowed acclimation period of 7 days in laboratory condition. Six rats each of the same sex were housed in polycarbonate cages bedding with husk, 20 to $24^{\circ} \mathrm{C}$ temperature and relative humidity between 30 to 70 percent The dark and light cycle of 12 hours each was maintained. Standard pelleted diet (M/s Ghosh Enterprise, Kolkata) with aquaguard pure water in glass bottles ad libitum were fed to the animals. Consumption quantity of food by the animals was comparable with that of the control group. The principles of laboratory animal care were followed according to the instructions by the Institutional Animal Ethics Committee. ${ }^{14}$

Diabetes was induced in all the rats except in the healthy controls (Gr.I) by Streptozotocin through intraperitoneal route. Hyperglycemia was confirmed by the elevated glucose level in plasma, determined at $48 \mathrm{~h}$ after injection. Hyperglycemic rats were included for the study along with the healthy control animals.

\section{Study design}

The animals were grouped into four of six rats each. Group I rats (Healthy and Normal) administered with double distilled water along with the feed. Group II rats (Diabetic control) were also fed with distilled water. Group III rats (Diabetic with extract) were fed with aqueous extract of Swietenia macrophylla seeds $(2 \mathrm{gm} / \mathrm{kg}$ body weight) daily. Group IV rats (Diabetic with Metformin) were fed with the aqueous extract and Metformin (10mg/ kg body weight) daily. All the rats were studied for 30days.

Collection and preparation of samples: The blood samples were collected from the tail veins aseptically in vials with heparin and centrifuged at $3000 \mathrm{rpm}$ for 10 minutes. The plasma was separated and used for biochemical tests. For in vitro study, packed red cells were washed with $\mathrm{NaCl}(0.9 \%)$, the ghost and intact cells were removed by centrifugation at $4^{\circ} \mathrm{C}, 20,000 \mathrm{rpm}$ for 30 minutes. The RBCs were washed with normal saline, and haemolysate prepared with chilled distilled water.

Biochemical tests: Plasma glucose, glycosylated haemoglobin and other biochemical tests were done with the help of spectrophotometer (Electronic Corporation of India limited) using standardized reagent kits and in the department of Biochemistry, Nilratan Sircar Medical College, Kolkata.

Assay of carbonic anhydrase activity: The assay system contained $100 \mu$ l of sample (Hemolysates) in $1.4 \mathrm{ml}$ of $0.05 \mathrm{M}$ Tris-SO4 buffer $(\mathrm{pH} 7)$ and $1.5 \mathrm{~mL}$ of $3 \mathrm{mM}$ p-nitrophenyl acetate. The change in absorbance at $348 \mathrm{~nm}$ was measured over a period of $3 \mathrm{~min}$, before and after adding the sample. One unit of enzyme activity was expressed as $1 \mu \mathrm{mol}$ of released $\mathrm{p}$-nitrophenol per minute at room temperature. All chemicals for carbonic anhydrase activity assay were obtained from Merck Chemicals. ${ }^{6}$

Data were expressed as mean $\pm \mathrm{SD}$, student's T- test was done for comparison, p-value less than 0.05 was considered significant. Statistical Analysis Data were statistically analyzed using Microsoft Excel and SPSS-16.

\section{Results with discussion}

Clinical and biochemical parameters of our study subjects have been depicted in Table 1. There were no significant changes in the body weights among the different groups of the animals, but the changes in blood glucose levels and HbAlc \% and lipid parameters were observed during the study. There is significant increase in erythrocyte CA activity along with blood glucose levels in the diabetic rats (Group II) compared to the healthy controls (Gr. I) (Figure 1).

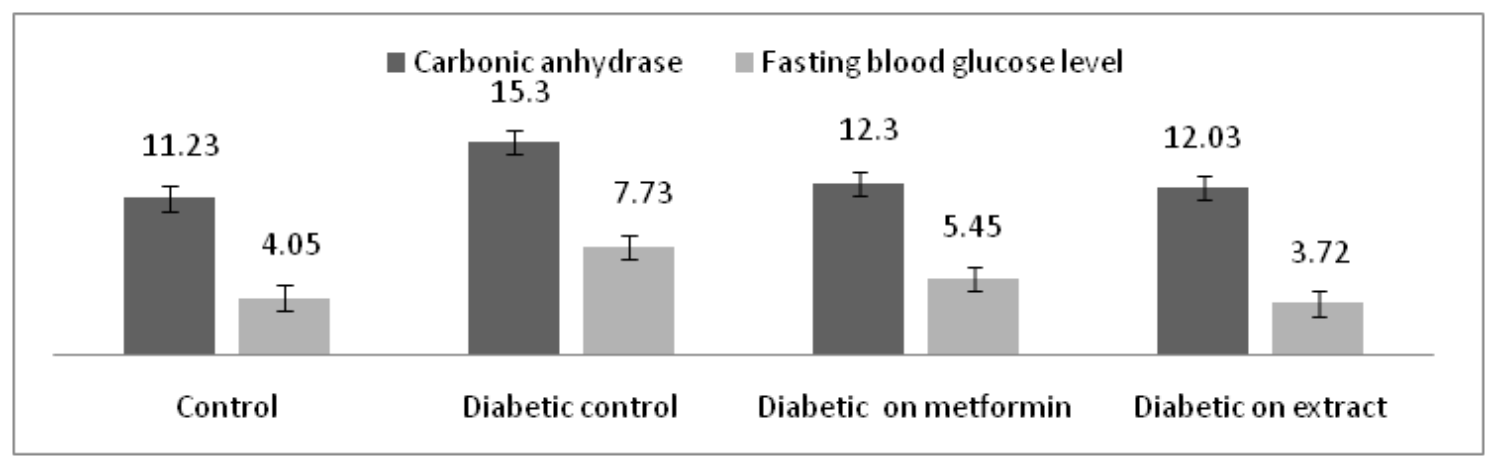

Figure I Carbonic anhydrase and Fasting blood glucose levels.

Pair two tail student's T test was done. Values were given as mean $\pm \mathrm{SD}$. Indicate the level of significance in comparison to diabetic control (Gr. II) ${ }^{\mathrm{a}} \mathrm{P}<0.05,{ }^{\mathrm{b}} \mathrm{p}<0.01$.

This observation agrees with our previous report. ${ }^{14}$ During 30days of treatment with the extract, the plasma glucose level significantly came down in Group IV animals. The similar trend has been observed with the treatment with metformin (Gr.III), an established hypoglycemic agent (Figure 1).

The CA activity in the current study is positively correlated $(\mathrm{r}=0.886, \mathrm{p}<0.001)$ with the blood glucose levels (Figure 2). This observation also supports our earlier findings. ${ }^{14,15}$ During 30days of treatment with the extract, the plasma glucose level significantly came 
down in Group IV animals. The similar trend has been observed with the treatment with metformin (Gr.III), an established hypoglycemic agent (Figure 1).

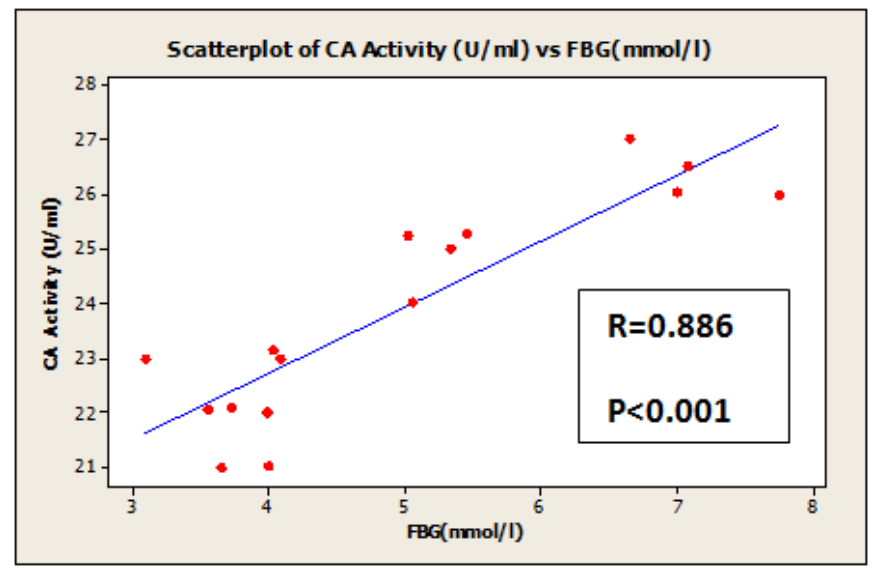

Figure $\mathbf{2}$ The CA activity with the Fasting blood glucose levels.

Moreover, our study also demonstrates association of these enzyme activities with dyslipidemia. Our results show significant positive relationship of erythrocyte $\mathrm{CA}$ activity with the total cholesterol $(\mathrm{r}=0.886, \mathrm{p}<0.001)$, triglyceride $(\mathrm{r}=0.886, \mathrm{p}<0.001)$ and LDL cholesterol levels $(\mathrm{r}=0.886, \mathrm{p}<0.001)$ as depicted in Figure $3-5$ respectively. These findings are also in agreement with the previous study by some of us, where we observed significantly higher levels of total cholesterol and triglycerides with a concomitant increase in serum malondialdehyde concentration and carbonic anhydrase activity in hypertensive patients. ${ }^{17}$

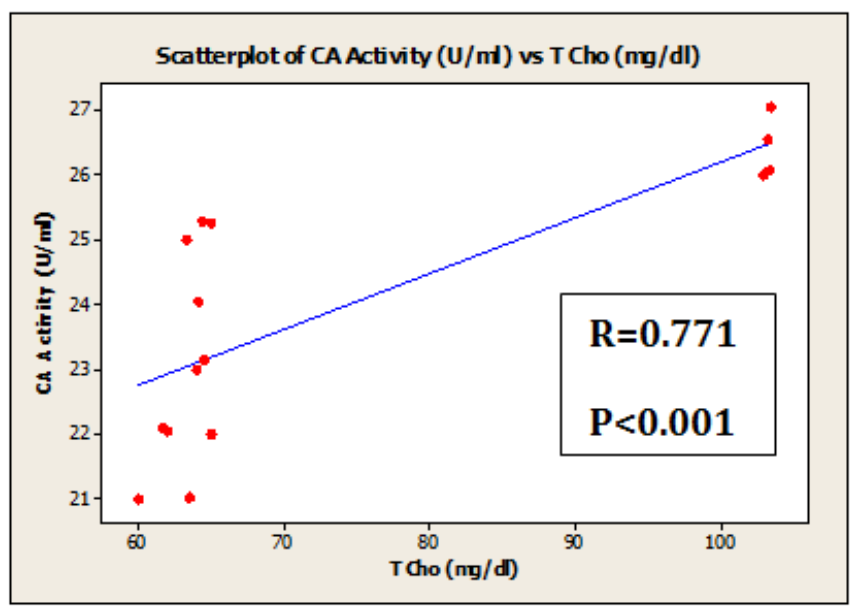

Figure $3 \mathrm{CA}$ activities with the total cholesterol levels.

Though hyperlipidemia is a common association of hyperglycemia in Diabetes Mellitus but association of increase CA activity in RBC in these situations reflects metabolic alteration in the tissues like liver, adipocytes and muscles. Previous study reported a role of carbonic anhydrase in hepatic lipogenesis at the level of pyruvate carboxylation. ${ }^{9}$ Though the systematic study of CA as a metabolic enzyme are insufficient, CA evolved as an enzyme of trans-membrane facilitated $\mathrm{CO}_{2}$ transport and take on a secondary metabolic role. Alteration of erythrocyte CA activity probably represents the overall metabolic state of the tissues. ${ }^{18}$ The CA mediated nitric oxide (NO) generation is another important aspect to understand correlation ship of CA activity with the increase blood flow and metabolic activity in different tissues and organs. ${ }^{19}$ The Group IV animals, receiving extract, had significant reduction of total cholesterol, triglyceride as well as LDL cholesterol levels in plasma, compared to diabetic control (Group II) animals (Table 1). The reduction of blood glucose level under the Swietenia macrophylla seeds also agrees with our earlier findings. ${ }^{14}$

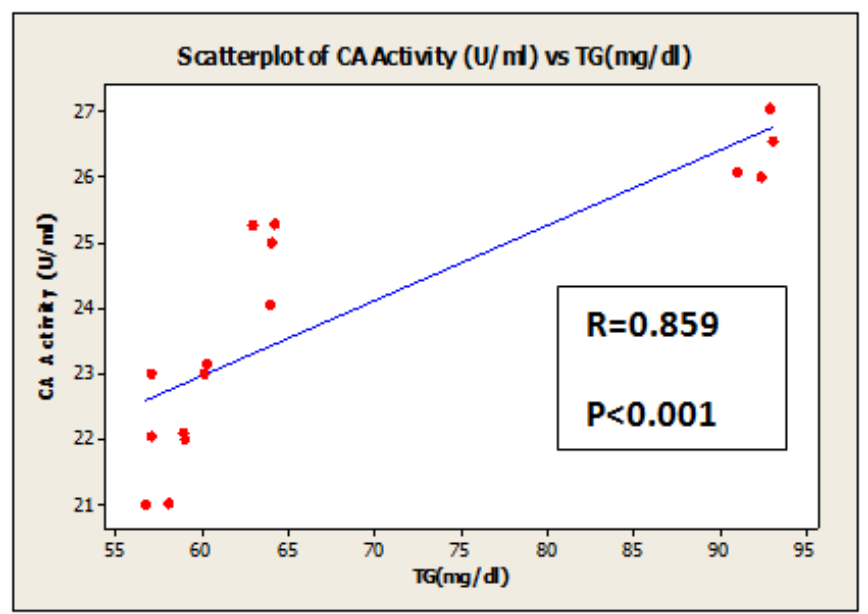

Figure $4 \mathrm{CA}$ activities with the triglyceride levels.

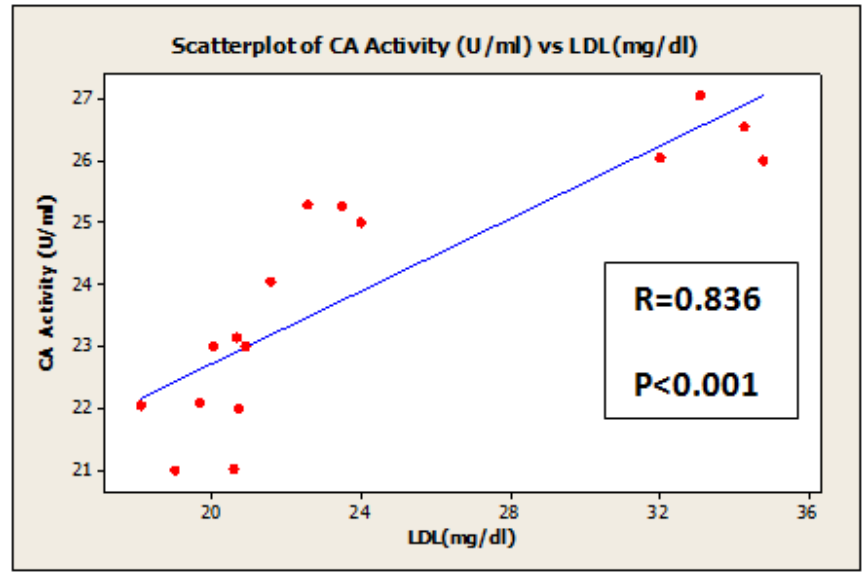

Figure $5 \mathrm{CA}$ activities with the LDL cholesterol levels.

In the current study, we have further wanted to observe weather the extract of Swietenia macrophylla, a phytoconstituents, which effectively lowers the blood glucose as well as cholesterol and triglyceride levels, can also inhibit the CA activity.

Presently two classes of compounds, the metal complexing anions (such as cyanide, cyanate, thiocyanate, azide, hydrogen sulfide, etc) and the sulfonamides, sulfamates or sulfonamides, are used as carbonic anhydrases inhibitors. These ubiquitous enzymes are present different tissues and in different isoforms. So they represent an attractive goal for the design of inhibitors with biomedical applications. CA inhibitors are mainly used as antiglaucoma, antitumor, antiobesity anticonvulsants, antimicrobials and antifungals agents. Besides they are also used as diagnostic tools for tumors. ${ }^{3}$

Table 1 \&Figure 1 indicates there is significant reduction of erythrocyte CA activity under the effect of this extract. The in vitro experiment also demonstrate inhibition of erythrocyte CA activity by the extract and it is comparable with the effect of acetazolamide, an established CA inhibitor as depicted in Table 2 \&Figure 6. 
Table I Biochemical parameters in the experimental rats

\begin{tabular}{lllll}
\hline Parameters & $\begin{array}{l}\text { Group I } \\
\text { (Normal Control) }\end{array}$ & $\begin{array}{l}\text { Group II } \\
\text { Diabetic Control) }\end{array}$ & $\begin{array}{l}\text { Group III } \\
\text { (Diabetic Rats With Meformin) }\end{array}$ & $\begin{array}{l}\text { Group IV } \\
\text { (Diabetic Rats With Extract) }\end{array}$ \\
\hline $\begin{array}{l}\text { Plasma glucose } \\
\text { level [mg/dl] }\end{array}$ & $72.73 \pm 4$ & $139.33 \pm 9.04$ & $67 \pm 9.23^{\mathrm{b}}$ & $98.66 \pm 9.26$ \\
HbAIc(\%) & $5.5 \pm 1.2$ & $5.7 \pm 1.04$ & $4.9 \pm 0.9$ & $5.0 \pm 1.11$ \\
Urea $(\mathrm{mg} / \mathrm{dl})$ & $22.95 \pm 2.43$ & $24.45 \pm 3.4$ & $20.05 \pm 2.11$ & $19.56 \pm 1.4$ \\
$\begin{array}{l}\text { Creatinine }(\mathrm{mg} / \mathrm{dl}) \\
\text { Plasma total } \\
\text { cholesterol }(\mathrm{mg} / \mathrm{dl})\end{array}$ & $0.5 \pm 0.09$ & $0.7 \pm 0.07$ & $0.67 \pm 0.01$ & $0.4 \pm 0.02$ \\
$\begin{array}{l}\text { Plasma } \\
\text { triglyceride }(\mathrm{mg} / \mathrm{dl})\end{array}$ & $60 \pm 2.58$ & $103.28 \pm 8.3$ & $61.65 \pm 4.40$ & $64.42 \pm 3.3^{\mathrm{a}}$ \\
Asma LDL $(\mathrm{mg} / \mathrm{dl})$ & $20.71 \pm 2.13$ & $93 \pm 10.64$ & $64.14 \pm 8.19$ & $58.85 \pm 4.4 I^{\mathrm{b}}$ \\
Plasma HDL(mg/d) & $50.14 \pm 11.99$ & $34.28 \pm 7.8$ & $19.71 \pm 1.11$ & $22.57 \pm 5.3^{\mathrm{b}}$ \\
\hline
\end{tabular}

Table 2 In Vitro Study of Erythrocyte CA activity under the effect of Acetazolamide $(\mathrm{mg} / \mathrm{dl})$ and extract of Swietenia macrophylla(mg/dl) in dose dependent manner

\begin{tabular}{lll}
\hline $\begin{array}{l}\text { Concentration of Acetazolamide and } \\
\text { extract of Swietenia macrophylla seed }\end{array}$ & $\begin{array}{l}\text { CA activity under the effect of } \\
\text { Acetazolamide(mg/dl) }\end{array}$ & $\begin{array}{l}\text { CA activity under the effect } \\
\text { of extract of Swietenia macrophylla(mg/dl) }\end{array}$ \\
\hline 50 & $146.66 \pm 0.58$ & $190.36 \pm 0.47$ \\
100 & $115.66 \pm 0.47$ & $118.66 \pm 0.47$ \\
200 & $111.66 \pm 0.47$ & $76.66 \pm 0.47$ \\
400 & $96.66 \pm 0.47$ & $50.33 \pm 0.57$ \\
\hline
\end{tabular}

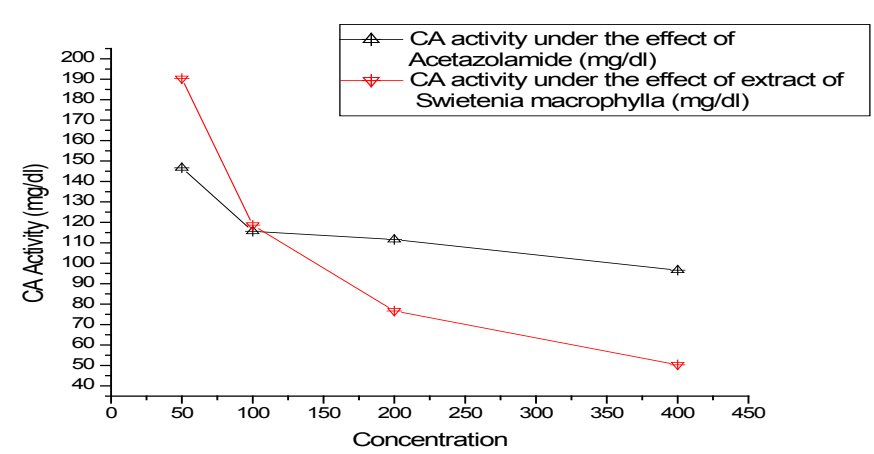

Figure 6 CA Activity under the effect of Acetazolamide and extract of Swietenia macrophylla $(\mathrm{mg} / \mathrm{dl})$.

Though it is yet to be established whether the increase of CA activity is the cause or effect in the insulin resistant conditions, but this reduction is associated with the improvement of the situation. As the modulation of CA activity is associated with the advance glycation end product, which we have demonstrated previously, ${ }^{5}$ the inhibitor of CA activity like the extract of Swietenia macrophylla seeds, may also be beneficial in this condition to prevent complications, where AGE compound has definite role to play. However, further study in this direction with bigger sample size, particularly at the tissue levels and preferably with the separated components of the seeds is needed.

\section{Conclusion}

Although we have a limited sample size and our study could not include the metabolic activity in tissues, our observation reveals that there is significant reduction of erythrocyte CA activity by the extract of Swietenia macrophylla seeds in streptozotocin induced diabetic rats along with effective lowering of blood glucose and lipid parameters.

\section{Acknowledgements}

None.

\section{Conflict of interest}

Author declares that there is no conflict of interest.

\section{References}

1. Supuran CT. Carbonic anhydrases as drug targets--an overview. Curr Top Med Chem. 2007;7(9):825-33.

2. Carter MJ, Parsons DS. The Isoenzymes of Carbonic Anhydrase: Tissue, subcellular Distribution and Functional Significance, with Particular Reference to the Intestinal Tract. J Physiol. 1971;215(1):71-94.

3. Chegwidden WR, Dodgson SJ, Spencer IM. The roles of carbonic anhydrase in metabolism, cell growth and cancer in animals. In: Chegwidden WR, editor. The Carbonic Anhydrases. 2000;90:343-363.

4. Sly WS, Emmett DH, Whyte MP, et al. Carbonic Anhydrase II DeficiencyIdentified as the Primary Defect in the Autosomal Recessive Syndrome of Osteopetrosis with Renal Tubular Acidosis an Calcification. Proc Natl Acad Sci. 1983;80(9):2752-2756.

5. Biswas UK, Kumar A. Study on the changes of Carbonic Anhydrase activity in insulin resistance and the effect of methylglyoxal. J Pak Med Assoc. 2012;6(5):417-421.

6. Das S, Biswas UK, Kumar A, et al. A study of serum carbonic anhydrase activity, uric acid, C-reactive protein levels and lipid parameter in patient with psoriasis. Nepal Journal of Dermatology, Venereology \& Leprology. 2003;11(1):20-27.

7. Parui R, Gambhir KK, Mehrotra PP. Changes in carbonic anhydrase may be the initial step of altered metabolism in hypertension. Biochem Int. 1991;23(4):779-789. 
8. Biswas UK, Kumar A. Does Assessment Of Carbonic Anhydrase Activity Support The Diagnosis of Various Thyroid Disorders. Asian Pacific Journal of Tropical Disease. 2013;4(Suppl 1):S338-S341.

9. Biswas UK, Kumar A. Study on Lipid Profile, Oxidation Stress and Carbonic Anhydrase Activity in Patients With Essential Hypertension. Journal of Clinical and Diagnostic Research. 2010;4(6):3414-3420.

10. Gitto R, Agnello S, Ferro S, et al. Identification of Potent and Selective Human Carbonic AnhydraseVII (hCAVII) Inhibitors. Chem Med Chem. 2010;5(6):823-826.

11. Simone DG, Supuran CT. Antiobesity carbonic anhydrase inhibitors. Curr Top Med Chem. 2007;7(9):879-884.

12. Supuran CT, Di Fiore A, De Simone G. Carbonic anhydrase inhibitors as emerging drugs for the treatment of obesity. Expert Opin Emerg Drugs. 2008;13(2):383-392.

13. Dutta M, Raychaudhuri U, Chakraborty R, et al. Sub-chronic toxicity study of the seeds of Swietenia macrophylla in wister rats. Sci Cult. 2012;78:78-83.

14. Dutta M, Biswas UK, Chakraborty R, et al. Antidiabetic and antioxidant effect of Swietenia macrophylla seeds in experimental type II diabetic rats. Int J Diabetes Dev Ctries. 2013;33(1):60-65.
15. Dutta M, Biswas UK, Chakraborty R, et al. Enhanced antioxidant enzyme activity in tissues and reduced total oxidative stress in plasma by the effect of Swietenia macrophylla king seeds in type II diabetes rats. International J Herbal Medicine. 2014;1(6):31-36.

16. Dutta M, Biswas UK, Chakraborty R, et al. Regeneration of pancreatic $\beta$-cells on streptozotocin induced diabetic rats under the effect of Swietenia macrophylla seeds. International $J$ Green Pharmacy. 2012;6(4):336-339.

17. Lynch CJ, Fox H, Hazen SA, et al. Role of hepatic carbonic anhydrase in de novo lipogenesis. Biochem J. 1995;310(pt 1):197-202.

18. Henry RP. Multiple Roles of Carbonic Anhydrase in Cellular Transport and Metabolism. Ann Rev Physiol. 1996;58:523-538.

19. Aamand R, Dalsgaard T, Jensen FB, et al. Generation of Nitric Oxide From Nitrite By Carbonic Anhydrase: A Possible Link Between Metabolic Activity and Vasodilatation. Am J Physiol Heart Circ Physiol. 2009;297(6):H2068-2074. 